\title{
BE A GAME CHANGER: MAKE A DIFFERENCE
}

\section{Dr. Justin Jeya Amutha*|Mrs. Devi Nanjapppan**}

*Associate professor, Smt. Nagarathnamma College of Nursing, Bangalore, India.

**Principal, Smt. Nagarathnamma College of Nursing, Bangalore, India.

DOI: http://doi.org/10.47211/trr.2021.v07i02.002

\section{ABSTRACT:}

The whole world is struggling for something in life. They all are players of their respective fields but the one who wins are the ordinary people who made a shift in the technique that most of the people perform. The winners are mostly the game changer. The change things in a way that is appreciable. They are the front-runners and look up to, learn from, and get inspired by. Game-changers were broadly conceptualized as macro-trends that are perceived to change the rules of the game, that is, to change how society is organized and defined by today's understandings, values, institutions, and social relationships. They see the world differently. They don't just seek to imitate the success of others, to compete in the markets of today, to frame themselves by their relative differences to competitors instead they play their own game.

Key Words: Game changer, Audacious, Adorn, yearn.

\section{ABOUT AUTHORS:}

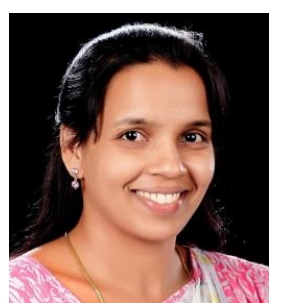

Dr. Justin Jeya Amutha, Associate Professor Smt. Nagarathnamma College of Nursing, Bangalore, India. She is active researcher with many publications in her name.

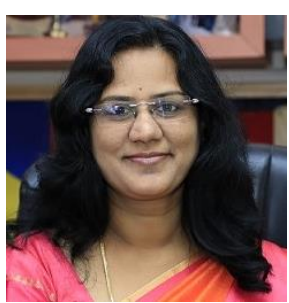

Professor Devi Nanjapppan is Principal, Smt. Nagarathnamma College of Nursing, Bangalore, India. She has attended various Seminars and conferences. 


\section{INTRODUCTION:}

\section{"BE A GAME CHANGER, THE WORLD IS ALREADY FULL OF PLAYERS"}

Every organisation needs game-changers: they identify programme opportunities others don't and come up with innovative ideas others overlook. They think differently and have the power to disrupt and transform the landscape in their world. They permanently live outside of the comfort zone, break the rules and take hoary old clichés like " blue sky thinking" and "pushing the envelope" to whole new levels. In the fast-paced world of digital transformation, they are even more vital to have in an organisation. Indeed, game-changers not only alter the landscape of a company but entire organizations and sectors, too.

DEFINITION:

A newly introduced element or factor that changes an existing situation or activity in a significant way.

COMMON TRAITS TO CHANGE GAME:

There is no one way to change the game, but there are definitely some common traits:

1. Audacious - Gamechangers are visionary and innovative, but also daring and original; they seek to shape the future to their advantage.

2. Purposeful - They seek to make life better, in some relevant and inspiring way; they have a higher motive than just making money.

3. Networked - Gamechangers harness the power of networks, digital and physical, both business and customer networks, to exponentially reach further faster.

4. Intelligent - They use big data analytics and algorithms, machine learning and $\mathrm{Al}$, to be smart and efficient, personal and predictive.

5. Collaborative - Gamechangers work with others, from ecosystems to platforms, social networks and cocreation, to achieve more together.

6. Enabling - They focus not on what they do, but what they enable people to do; and thereby redefine their marketspace, find new opportunities and redefine value.

7. Commercial - Gamechangers take a longer-term perspective, adopting new business models, and recalibrating the measures of progress and success.

\section{CHARACTERIZATION OF GAME CHANGERS:}

Game changers have several traits and characterize that such leaders, including that they:

- $\quad$ are described innovators or problem solvers

- always look at the bright side when things go south

- think outside the box and keep pushing their boundaries

- $\quad$ never settle for anything that's less than ordinary

- $\quad$ have self-awareness and show great empathy towards others

Highly intuitive and deep thinkers, game changers find it easy to 'connect the dots'. They accept challenges and are comfortable taking risks. Some may consider them troublemakers (they are happy to rock the boat), while others consider them geniuses.

\section{WHY SHOULD LEADERS BE THE GAME CHANGERS?}

Managers and supervisors form an integral part of your organization. Apart from having good managerial skills, they also need to be the game changers. Game changers have the inherent skills of problem solving, multitasking, and judging potential in people. Even if these are not inherent qualities, those who lack them can learn how to be the game changers, if they want to be good leaders. Here are four qualities that differentiate exceptional change leaders:

1. Empathetic to the needs of the employees

2. Good communications skills

3. They can identify the root cause of the problem and implement logical solutions

4. Inspirational, with the ability to provide feedback positively

\section{STEPS TO BE A GAME CHANGER IN THE LIVES OF PEOPLE :}

\section{YEARN:}

It starts with a yearning to make a difference in someone's life. You can't fake this as and the difference between being genuinely yearning to make a difference and pretending-to-want-to-make-a-difference is like the difference between black and white.

2. LEARN:

The next step is to learn what matters most to the person. There is a simple trick to learn what matters most. It is to listen way more than you talk. If you listen to anyone sooner than later he or she will talk about what matters most. However, if you talk more than you listen, you will scare them away from your network sooner than later. 


\section{ARTICLES}

\section{EARN:}

You need to earn the trust of the person in consideration that you have valuable help to offer.

\section{ADORN:}

Adorn is to make something more attractive. In this case, you bring everything you have got to bear to enrich the life of the person in consideration.

\section{TURN:}

Nothing in life is static, not your life and not their life. It changes all the time and what matters most to them today. When you truly care, you will turn to the "new" what matters most so you are tracking them to help them along the way. In fact, if you play your part well, you will be right beside them as they turn new chapters in their life. You will be part of their extended family.

\section{UPTURN:}

If you are passionately engaged in all the above steps, there is no other outcome possible except a measurable upturn in the life of the person in consideration. It is not a notional upturn but something that can be seen and measured. It is the only way you get real feedback on whether what you are doing is working or not.

\section{BURN:}

This is where you burn the midnight oil to keep ensuring that you are a better YOU as compared to yesterday. If you are not growing, you can't be helping others to grow. Even if you are doing very well today, you will slide down without continuous investment in yourself.

Honestly, if you want to be a game changer in the lives of people, it will have to start with changing the game of your own life for the better.

\section{WHAT ARE THE SECRETS TO SUCCESS IN CREATING GAMECHANGER CULTURES AND ORGANIZATIONS IN THE CONNECTED ECONOMY?}

We live in an incredible time. More change in the next 10 years than in the last 250 years.

- New technologies are transforming the ways in which we live and work. Technologies enable incredible change. It is how we unlock their potential that matters.

- Digital platforms connecting buyers and sellers in new ways, blockchain having the potential to transform relationships and trust

- $\quad 3 d$ printing having the potential to transform value chains to deliver anything personalised and ondemand, Al and robotics giving us the capabilities to be superhuman in our minds and bodies.

These are just some of the fantastic new capabilities that enable us to innovate beyond what we can even imagine today. The future isn't like the future used to be. We cannot just evolve or extrapolate the past. Today's future is discontinuous, disruptive, and different.

It is imagination that will move us forwards unlocking the technological possibilities, applying them to real problems and opportunities, to drive innovation and growth in every industry, in every part of our lives.

\section{SUMMARY:}

The secret is the future mindset. To realize that the future is malleable. So we need to grab hold of it, and shape it in our own vision. This is what "gamechangers" do.

Many organisations might perceive they want a game-changer but, in reality, the individual's actions can prove unsettling for the board who then become resistant to the change. It is therefore important that the board and senior colleagues understand the role of the game-changer that the culture is supportive and there is an understanding of what they have been brought in to achieve. If everyone was a game-changer, organisations wouldn't function efficiently. But with the right blend of skills and characteristics to support them, their full potential can be harnessed without any downsides for the organisation or those around them. 


\section{ARTICLES}

\section{REFERENCES:}

1. Haxeltine A., B. Pel, A. Dumitru, R. Kemp, F. Avelino, M. Sogaard Jorgensen, J. Wittmayer, I. Kunze, J. Dorland, and T. Bauler. 2017. TRANSIT WP3 Deliverable D3.4 - consolidated version of TSI theory. TRANSIT: EU SSH.2013.3.2-1 grant agreement n. 613169

2. Hulme, M. 2009. Why we disagree about climate change: understanding controversy, inaction and opportunity. Cambridge University Press, Cambridge, UK. http://dx.doi.org/10.1017/ CBO9780511841200

3. Loorbach, D., F. Avelino, A. Haxeltine, J. M. Wittmayer, T. Oroidin, P. Weaver, and R. Kemp. 2016. The economic crisis as a game changer? Exploring the role of social construction in sustainability transitions. Ecology and Society 21(4):15. http://dx.doi.org/10.5751/ES-08761-210415

4. Moulaert, F. 2009. Social innovation: institutionally embedded, territorially (re)produced. Pages 11-23 in D. MacCallum, F.

5. Moulaert, J. Hillier, and V. Haddock, editors. Social innovation and territorial development. Routledge, London, UK.

6. Olsson, P., M.-L. Moore, F. Westley, and D. McCarthy. 2017. The concept of the Anthropocene as a game-changer: a new context for social innovation and transformations to sustainability. Ecology and Society 22(2):31. http://dx.doi.org/10.5751/ES-09310-220231

7. Pel, B., G. Wallen born, and T. Bauler. 2016. Emergent transformation games: exploring social innovation agency and activation through the case of the Belgian electricity blackout threat. Ecology and Society 21(2):17. http://dx.doi.org/10.5751/ ES-08346-210217

8. Prasad, S. 2016. Innovating at the margins: the system of rice intensification in India and transformative social innovation. Ecology and Society 21(4):7. http://dx.doi.org/10.5751/ES-08718-210407

9. Swilling, M. 2016. Africa's game changers and the catalysts of social and system innovation. Ecology and Society 21(1):37. http:// dx.doi.org/10.5751/ES-08226-210137

10. Urry, J. 2007. Mobilities. Polity Press, Cambridge, UK. Van Dyck, B. and P. Van den Broeck. 2013. Social innovation: a territorial process. Pages 131-141 in F. Moulaert, D. MacCallum, A. Mehmood, and A. Hamdouch, editors.

11. The international handbook on social innovation: collective action, social learning and transdisciplinary research. Edward Elgar, Cheltenham, UK. http://dx.doi.org/10.4337/9781849809993.00021

12. Westley, F. R., K. A. McGowan, N. Antadze, J. Blacklock, and O. Tjornbo. 2016. How game changers catalyzed, disrupted, and incentivized social innovation: three historical cases of nature conservation, assimilation, and women's rights. Ecology and Society 21(4):13.

13. https://www.forwardfocusinc.com/jumpstart-change/why-its-essential-for-leaders-to-be-the-gamechanger/

14. https://www.rialtoconsultancy.com/news_insights/game-changers-what-do-they-do-differently/

15. https://www.bankersadda.com/be-a-game-changer-the-world-is-already-full-of-players. 